\title{
ARTICLES
}

\section{ECONOMIC PREMIUM PRINCIPLES IN INSURANCE AND THE CAPITAL ASSET PRICING MODEL}

\author{
By HeInz H. MüLleR \\ University of Zürich
}

\begin{abstract}
An insurance company is considered as an intermediary between policyholders and the capital market. By applying the traditional and the generalized version of the capital asset pricing model, a class of premium principles can be derived. This class is fully compatible with Bühlmann's economic premium principle. Moreover, insurance premiums can be directly related to risk premiums on the stock exchange.
\end{abstract}

KEYWORDS

Capital asset pricing model; insurance premiums; price equilibrium; Neumann utility.

\section{INTRODUCTION}

Premium calculation is one of the main objectives of risk theory. The extensive and sophisticated literature on this topic is summarized in the recent book by GOOVAERTS, DE VYLDER and HAEZENDONCK (1984).

On the other hand, equilibrium conditions on capital markets are a central issue of the theory of corporate finance. Based on mean-variance analysis, SHARPE (1964) and LINTNER (1965) derived the capital asset pricing model (CAPM). The CAPM-formula is an equilibrium condition which relates risk premiums to the covariances between the returns on the market portfolio and the corresponding assets. Later, the CAPM relationship was generalized to the case of risk evaluation by Neumann utilities (see e.g. MERTON (1982), pp. 614-618).

There are only a few recent papers in which elements of risk theory have been combined with models of corporate finance and economic theory. BÜHLMANN (1980, 1984) and LIENHARD (1986) derived a class of premium principles by applying a general equilibrium approach to the insurance market. BORCH's analysis (1986) of the insurance market is based on a slightly generalized version of the CAPM-relationship. KAHANE (1979) stressed the importance of investment income on premiums and made a first step in order to apply the traditional capital asset pricing model to premium calculation.

The aim of the present work is to unify the ideas of the articles mentioned above by means of a simple model. In accordance with corporate finance, an insurance company is considered as an intermediary between policyholders and the 
capital market. Hence, a share of an insurance company is a combination of claims on the assets representing the reserves and the liabilities stemming from the insurance contracts issued by the company (see also KAHANE (1979), BORCH (1986)). By application of the traditional and the generalized versions of the CAPM-formula, insurance premiums can be related to risk premiums on stocks. The resulting class of premium principles corresponds exactly to the class of premium principles derived by BüHLMANN (1980) and LIENHARD (1986). Hence, at least in this respect, risk theory and the theory of corporate finance lead to perfectly compatible conclusions. Our main result, however, consists in a relationship between insurance premiums and risk premiums on stocks which could also be useful for empirical research.

\section{THE CAPITAL ASSET PRICING MODEL (CAPM)}

\subsection{The Sharpe-Lintner Model}

In the Sharpe-Lintner model there is one risk-free asset $(h=0)$ and there are $n$ risky assets $(h=1, \ldots, n)$. The rates of return are given by:

the deterministic rate of interest $R_{0}$ for the risk-free asset $h=0$;

the stochastic rates of return $R_{1}, \ldots, R_{n}$ for the risky assets $h=1, \ldots, n$.

$m$ investors are characterized by:

their initial endowments represented by $(n+1)$-bundles of assets,

their preferences with respect to final wealth, which are assumed to be compatible with mean-variance analysis.

Furthermore, markets are assumed to be competitive. Short selling is possible, there are no transaction costs and in particular the risk-free asset can be borrowed and lent at the same rate of interest. For this model, Sharpe (1964) and LINTNER (1965) have shown that under mild regularity assumptions the rates of return $R_{0}, R_{1}, \ldots, R_{n}$ must satisfy the following equilibrium conditions (CAPM-relationship):

$$
E\left(R_{h}\right)-R_{0}=\frac{\operatorname{Cov}\left(R_{h}, R^{M}\right)}{\operatorname{Var}\left(R^{M}\right)}\left[E\left(R^{M}\right)-R_{0}\right] \quad(h=1, \ldots, n),
$$

where $R^{M}$ denotes the stochastic rate of return on the market portfolio. The market portfolio is defined as a portfolio made up of all assets in the economy held according to their market value weights.

Under the model assumptions, the market portfolio can be represented as a solution of an optimization problem. Analysing the optimality conditions leads to (1).

\subsection{The General Version of the Capital Asset Pricing Model}

From the theoretical point of view, portfolio evaluation by Neumann utilities is much more satisfactory than mean-variance analysis. 
A portfolio $x$ is of the form

$$
\boldsymbol{x}=\left(x_{0}, x_{1}, \ldots, x_{n}\right), \quad \text { with } \sum_{h=0}^{n} x_{h}=1
$$

and leads to the stochastic rate of return:

$$
R(x)=\sum_{h=0}^{n} x_{h} R_{h}
$$

A portfolio $x^{u}$ is called efficient relative to a Neumann utility $u: R \rightarrow R$ if it represents a solution of the optimization problem

$$
\max _{x \in R^{n+1}} E\{u[R(x)]\}
$$

subject to

$$
\sum_{h=0}^{n} x_{h}=1
$$

Under mild regularity conditions, efficient portfolios satisfy the generalized CAPM-relationship:

(2) $E\left(R_{h}\right)-R_{0}=\frac{\operatorname{Cov}\left\{u^{\prime}\left[R\left(x^{u}\right)\right], R_{h}\right\}}{\operatorname{Cov}\left\{u^{\prime}\left[R\left(x^{u}\right)\right], R\left(x^{u}\right)\right\}}\left\{E\left[R\left(x^{u}\right)\right]-R_{0}\right\} \quad(h=1, \ldots, n)$.

See e.g. MERTON (1982), Theorem 3.1. The generalized CAPM-relationship (2) can be easily derived from the optimality conditions,

$$
E\left\{\left(R_{h}-R_{0}\right) u^{\prime}\left[R\left(x^{u}\right)\right]\right\}=0 \quad(h=1, \ldots, n) .
$$

Furthermore, under regularity assumptions on the rates of return, there exist classes of Neumann utilities $\mathscr{U}$ with the following property:

If the preferences of investors $i=1, \ldots, m$ are given by the Neumann utilities $u^{i} \in \mathscr{U}$, then there exists $u_{M} \in \mathscr{U}$ such that the market portfolio is efficient relative to $u_{M}$.

CASS and STiglitz (1970) show that the following classes have this property:

$$
\begin{aligned}
& \mathscr{U}(c)=\left\{u \mid u^{\prime}(w)=(\beta w / c+\eta)^{-c}, \beta>0\right\}, c \in(-\infty, 0) \cup(0, \infty), \\
& \mathscr{U}(c)=\left\{u \mid u^{\prime}(w)=e^{-\alpha w}, \alpha>0\right\}, c=\infty .
\end{aligned}
$$

These classes are also well known in risk theory. According to Borch's theorem each of these classes leads to linear risk sharing. The union of these classes,

$$
\{u \mid u \in \mathscr{U}(c), c \in(-\infty, 0) \cup(0, \infty]\},
$$

is the HARA-class (Hyperbolic $A$ bsolute Risk $A$ version) which is characterized by

$$
-\frac{u^{\prime \prime}(w)}{u^{\prime}(w)}=\frac{1}{a+b w}>0
$$




\section{PREMIUM PRINCIPLES AND THE CAPITAL ASSET PRICING MODEL}

\subsection{The Model}

$m$ investors $(i=1, \ldots, m)$ face the following investment opportunities:

One risk-free asset with a deterministic rate of return $R_{0}$. This asset is assumed to be in net supply zero.

$n$ risky assets $(h=1, \ldots, n)$ representing the non-insurance sector of the economy. These assets are characterized by stochastic rates of return $R_{1}, \ldots, R_{n}$.

One risky asset $(h=n+1)$ representing the single insurance company of the economy. The stochastic rate of return is denoted by $R_{n+1}$ and will be analysed below.

3.1.1. The non-insurance sector. Let $W_{h}$ be the market value of all outstanding shares on investment opportunity $h(h=1, \ldots, n)$. Then the value of all risky noninsurance assets is given by

$$
K_{N}:=\sum_{h=1}^{n} W_{h}
$$

The market portfolio for this sector of the economy is of the form

$$
\boldsymbol{x}^{N}:=\frac{1}{K_{N}}\left(W_{1}, \ldots, W_{n}\right),
$$

i.e. all non-insurance assets are held in proportion to their markei values.

For the corresponding stochastic market rate of return, one obtains

$$
R^{N}:=\frac{1}{K_{N}} \sum_{i=1}^{n} W_{i} R_{i}
$$

3.1.2. The insurance company. As mentioned in the introduction, the insurance company acts as an intermediary between policyholders and the capital market. In order to cover the total insurance risk $X$, the company receives the amount $\pi$ as premium payments from the policyholders. Let us assume that the amount $K_{I}$ is raised from shareholders and that the company invests its total reserves $K_{I}+\pi$ in the risk-free asset $h=0$. In a perfect capital market this assumption is not restrictive. Shareholders are able to offset any investment policy of the insurance company by their own investment decisions. Then, the final value of the company is given by

$$
\left(K_{I}+\pi\right)\left(1+R_{0}\right)-X
$$

and the rate of return on its share is

$$
R_{n+1}\left(K_{I}\right)=R_{0}+\frac{\pi\left(1+R_{0}\right)-X}{K_{I}} .
$$

Shareholders can themselves borrow and lend at the risk-free rate $R_{0}(h=0)$ and 
are fully liable for losses of the insurance company. Therefore, it does not matter whether the shareholders lend their money to the insurance company or whether they invest it themselves in the risk-free asset. Hence, without influencing the risk allocation in the economy, $K_{I}$ may be fixed at an arbitrary level. For our purposes, one can in particular assume

$$
K_{I}=-\pi^{(1)} .
$$

With this normalization, the rate of return becomes

$$
R_{n+1}=\frac{X}{\pi}-1^{(2)}
$$

and holding a share of the insurance company is nothing else than short selling insurance contracts. Of course, the liability condition is crucial for our normalization. Otherwise a share of the insurance company would be a combination of a risk-free investment and a short position in insurance contracts.

3.1.3. The market portfolio. Since the risk-free asset is in net supply zero, the market portfolio is of the form

$$
x^{M}=\frac{1}{K}\left(0, W_{1}, \ldots, W_{n}, K_{I}\right), \quad \text { with } K:=K_{N}+K_{I}=\sum_{h=1}^{n} W_{h}+K_{I} .
$$

Owing to the normalization

$$
K_{l}=-\pi
$$

one obtains

$$
K=K_{N}-\pi
$$

and the market portfolio may be decomposed into

$$
\boldsymbol{x}^{M}=\left(0, \frac{K_{N}}{K_{N}-\pi} \boldsymbol{x}^{N},-\frac{\pi}{K_{N}-\pi}\right) .
$$

The corresponding rate of return is given by

$$
R^{M}=\frac{K_{N}}{K_{N}-\pi} R^{N}-\frac{\pi}{K_{N}-\pi}\left(\frac{X}{\pi}-1\right) .
$$

Equation (12) relates the insurance risk $X$ and the insurance premium $\pi$ to the

1. In other words, investors $i=1, \ldots, m$ receive the amount $\pi$ against the obligation to cover the risk $X$. Without perfect liability a lower bound on $K_{I}$ would be imposed by a condition of the type

$$
\text { prob }\left[\left(K_{I}+\pi\right)\left(1+R_{0}\right)-X \geqslant 0\right] \geqslant 1-\varepsilon .
$$

2. Thus, $R_{n+1}$ is the rate of return on insurance contracts. Since investors hold a short position it is not surprising that typically

$$
\frac{E(X)}{\pi}-1<R_{0}
$$

holds. 
market rate of return $R^{M}$. Applying the traditional and generalized versions of the CAPM-formula to $R^{M}$ and $R_{n+1}=(X / \pi)-1$ allows us to derive a class of premium principles.

\subsection{Premium Principles Based on the Traditional Capital Asset Pricing Model}

In this section the Sharpe-Lintner model will be applied to premium calculation. Since the Sharpe-Lintner model is based on $(\mu, \sigma)$-analysis, the resulting premium principles will only depend on the first two moments of the underlying distributions. First of all, we shall see that the special case where $X$ and $R^{N}$ are uncorrelated leads to the well-known variance principle. Later, the general case will be cealt with, where the insurance risk $X$ and the rate of return on the noninsurance sector $R^{N}$ may be correlated.

3.2.1. Application of the Sharpe-Lintner model. As already mentioned, the CAPM-relationship (8) has to be applied on (12). For $h=n+1$, this leads to

$$
E(X / \pi)-1-R_{0}=\beta\left\{E\left(R^{M}\right)-R_{0}\right\}, \quad \text { with } \beta=\frac{\operatorname{Cov}\left(X / \pi, R^{M}\right)}{\operatorname{Var}\left(R^{M}\right)} .
$$

Using (12) one obtains

$$
\begin{aligned}
\operatorname{Cov}\left(X / \pi, R^{M}\right)= & \frac{1}{\pi} \frac{K_{N}}{K_{N}-\pi} \operatorname{Cov}\left(X, R^{N}\right)-\frac{1}{\pi} \frac{1}{K_{N}-\pi} \operatorname{Var}(X) \\
\operatorname{Var}\left(R^{M}\right)= & \left(\frac{K_{N}}{K_{N}-\pi}\right)^{2} \operatorname{Var}\left(R^{N}\right)+\left(\frac{1}{K_{N}-\pi}\right)^{2} \operatorname{Var}(X) \\
& -\frac{2 K_{N}}{\left(K_{N}-\pi\right)^{2}} \operatorname{Cov}\left(X, R^{N}\right) \\
E\left(R^{M}\right)= & \frac{K_{N}}{K_{N}-\pi} E\left(R^{N}\right)-\frac{\pi}{K_{N}-\pi}[E(X / \pi)-1]
\end{aligned}
$$

Inserting

$$
\beta=\frac{K_{N}-\pi}{\pi} \frac{K_{N} \operatorname{Cov}\left(X, R^{N}\right)-\operatorname{Var}(X)}{K_{N}^{2} \operatorname{Var}\left(R^{N}\right)+\operatorname{Var}(X)-2 K_{N} \operatorname{Cov}\left(X, R^{N}\right)}
$$

into (13) yields

$$
\begin{aligned}
\frac{E(X)}{\pi}-1-R_{0}= & \frac{K_{N} \operatorname{Cov}\left(X, R^{N}\right)-\operatorname{Var}(X)}{K_{N}^{2} \operatorname{Var}\left(R^{N}\right)+\operatorname{Var}(X)-2 K_{N} \operatorname{Cov}\left(X, R^{N}\right)} \\
& \times\left\{\frac{K_{N}}{\pi}\left[E\left(R^{N}\right)-R_{0}\right]-\left[\frac{E(X)}{\pi}-1-R_{0}\right]\right\}
\end{aligned}
$$

or

$$
\begin{aligned}
& {\left[K_{N}^{2} \operatorname{Var}\left(R^{N}\right)-K_{N} \operatorname{Cov}\left(X, R^{N}\right)\right]\left[E(X)-\pi\left(1+R_{0}\right)\right]} \\
& \quad=\left[K_{N} \operatorname{Cov}\left(X, R^{N}\right)-\operatorname{Var}(X)\right] K_{N}\left[E\left(R^{N}\right)-R_{0}\right]
\end{aligned}
$$


By (12) we get

$$
\frac{\pi\left(1+R_{0}\right)-E(X)}{\left[E\left(R^{N}\right)-R_{0}\right] K_{N}}=\frac{\operatorname{Cov}\left(-X, R^{M}\right)}{\operatorname{Cov}\left(K_{N} R^{N}, R^{M}\right)} .
$$

Obviously $\pi\left(1+R_{0}\right)-E(X)$ is the net premium on the insurance risk $X$ and $\left[E\left(R^{N}\right)-R_{0}\right] K_{N}$ is the market risk premium on all non-insurance assets. Therefore (20) relates the premium on the insurance risk $X$ to the market risk premium on all non-insurance assets. This relationship allows for different interpretations.

3.2.2. The capital asset pricing model and the variance principle. Applying the decomposition formula (12) for the market return yields

$$
\frac{\pi\left(1+R_{0}\right)-E(X)}{\left[E\left(R^{N}\right)-R_{0}\right] K_{N}}=\frac{\operatorname{Var}(X)-\operatorname{Cov}\left(X, K_{N} R^{N}\right)}{\operatorname{Var}\left(K_{N} R^{N}\right)-\operatorname{Cov}\left(X, K_{N} R^{N}\right)} .
$$

In the special case

$$
\operatorname{Cov}\left(X, K_{N} R^{N}\right)=0
$$

i.e. if the risks of the insurance and the non-insurance sector are uncorrelated, (21) is reduced to

$$
\frac{\pi\left(1+R_{0}\right)-E(X)}{\left[E\left(R^{N}\right)-R_{0}\right] K_{N}}=\frac{\operatorname{Var}(X)}{\operatorname{Var}\left(K_{N} R^{N}\right)}
$$

In other words, the insurance risk $X$ and the non-insurance risk $K_{N} R^{N}$ are evaluated by the well-known variance principle.

In general, however, (22) does not hold and the covariance terms in (21) lead to a deviation from the variance principle. If $K_{N}, R_{0}, E\left(R^{N}\right), E(X), \operatorname{Var}(X)$, $\operatorname{Var}\left(R^{N}\right)$ and $\operatorname{Cov}\left(X, R^{N}\right)$ are known, the premium $\pi$ can be calculated by means of (21). In this sense (21) provides us with a premium principle which fully reflects capital market conditions and depends only on the first and second moments of the underlying distributions.

3.2.3. The capital asset pricing model and general equilibrium theory. BÜHLMANN $(1980,1984)$ applied general equilibrium concepts to a risk exchange market. He proved the existence of equilibrium prices in the continuous case and derived, together with LIENHARD (1986), explicit price formulae for all types of Neumann utilities belonging to the HARA-class.

If Bühlmann's concept is applied to our model, the premium for a risk $X$ is given by

$$
\varepsilon\left(X, R^{M}\right):=E\left[X \varphi\left(R^{M}\right)\right]
$$

where the price density $\varphi$ is defined by

$$
\varphi\left(R^{M}\right)=\frac{a-R^{M}}{a-E\left(R^{M}\right)}
$$

3. See also Lienhard (1986). 
Hence, one obtains

$$
\varepsilon\left(X, R^{M}\right)=-\frac{\operatorname{Cov}\left(X, R^{M}\right)}{a-E\left(R^{M}\right)}+E(X)
$$

and (20) becomes

$$
\frac{\pi\left(1+R_{0}\right)-E(X)}{\left[E\left(R^{N}\right)-R_{0}\right] K_{N}}=\frac{\varepsilon\left\{X-E(X), R^{M}\right\}}{\varepsilon\left\{K_{N}\left[E\left(R^{N}\right)-R^{N}\right], R^{M}\right\}} .
$$

The numerator of the right-hand side denotes the premium for the insurance risk $X-E(X)$ under the market rate of return $R^{M}$.

The denominator may be interpreted as the premium for the risk of the noninsurance sector $-K_{N}\left[R^{N}-E\left(R^{N}\right)\right]$ under the market rate $R^{M}$. Again the capital asset pricing model is perfectly compatible with risk theory.

\subsection{Premium Principles Based on the Generalized Capital Asset Pricing Model}

3.3.1. The general case. In this section the preferences of the $m$ investors are given by Neumann utilities $u^{i}: R \rightarrow R, i=1, \ldots, m$. Furthermore, one assumes

$$
u^{1}, \ldots, u^{m} \in \mathscr{U}(c)^{(4)} \quad \text { for some } c \in(-\infty, 0) \cup(0, \infty] .
$$

As we have seen in Section 2.2, this assumption implies:

There exists a Neumann utility $u_{M} \in \mathscr{U}(c)$, such that the market portfolio $R^{M}$ is efficient relative to $u_{M}$.

For $h=n+1, R\left(x^{u}\right)=R^{M}$ the generalized CAPM-relationship (2) leads to

(28) $E\left(R_{n+1}\right)-R_{0}=\frac{E\left\{u_{M}^{\prime}\left(R^{M}\right)\left[R_{n+1}-E\left(R_{n+1}\right)\right]\right\}}{E\left\{u_{M}^{\prime}\left(R^{M}\right)\left[R^{M}-E\left(R^{M}\right)\right]\right\}}\left[E\left(R^{M}\right)-R_{0}\right]$.

By (12) one obtains

$$
\begin{aligned}
& \frac{E(X)-\pi\left(1+R_{0}\right)}{\left[E\left(R^{N}\right)-R_{0}\right] K_{N}-\left[E(X)-\pi\left(1+R_{0}\right)\right]} \\
& \quad=\frac{E\left\{u_{M}{ }^{\prime}\left(R^{M}\right)[X-E(X)]\right\}}{E\left\{u_{M}^{\prime}\left(R^{M}\right)\left[R^{N}-E\left(R^{N}\right)\right] K_{N}\right\}-E\left\{u_{M}^{\prime}\left(R^{M}\right)[X-E(X)]\right\}}
\end{aligned}
$$

or

$$
\begin{aligned}
& \frac{\pi\left(1+R_{0}\right)-E(X)}{\left[E\left(R^{N}\right)-R_{0}\right] K_{N}}= \\
& \quad\left(\frac{E\left\{u_{M}^{\prime}\left(R^{M}\right)[X-E(X)]\right\}}{E\left\{u_{M}^{\prime}\left(R^{M}\right)\right\}}\right) /\left(\frac{E\left\{u_{M}^{\prime}\left(R^{M}\right)\left[E\left(R^{N}\right)-R^{N}\right] K_{N}\right\}}{E\left\{u_{M}^{\prime}\left(R^{M}\right)\right\}}\right)
\end{aligned}
$$

Now we can apply Bühlmann's concept again. Let

$$
\varphi\left(R^{M}\right):=\frac{u_{M}{ }^{\prime}\left(R^{M}\right)}{E\left\{u_{M}{ }^{\prime}\left(R^{M}\right)\right\}}
$$

4. $14(\mathrm{c})$ is defined by (3). 
be the price density and

$$
\varepsilon\left(Y, R^{M}\right):=E\left[Y \varphi\left(R^{M}\right)\right]
$$

be the premium for a risk $Y$ under the market rate of return $R^{M}$. Then (30) is of the form

$$
\frac{\pi\left(1+R_{0}\right)-E(X)}{\left[E\left(R^{N}\right)-R_{0}\right] K_{N}}=\frac{\varepsilon\left\{X-E(X), R^{M}\right\}}{\varepsilon\left\{K_{N}\left[E\left(R^{N}\right)-R^{N}\right], R^{M}\right\}} .
$$

For the price density given by (31), a straightforward calculation leads to

$$
\varphi\left(R^{M}\right)=\frac{\left(a+b R^{M}\right)^{-c}}{E\left[\left(a+b R^{M}\right)^{-c}\right]} \quad \text { with } b c>0
$$

for $c \in(-\infty, 0)$ or $c \in(0, \infty)$, and to

$$
\varphi\left(R^{M}\right)=\frac{e^{-b R^{M}}}{E\left[e^{-b R^{M}}\right]} \quad \text { with } b>0
$$

for $c=\infty$.

The formulae (34) and (35) correspond exactly to LIENHARD's (1986) results. This allows us to conclude that Bühlmann's premium concept for insurance risks and the generalized capital asset pricing model are compatible for the HARAclass.

\subsubsection{Special cases}

\section{The Traditional Capital Asset Pricing Model}

For $c=-1$, the Neumann utilities are quadratic, (34) coincides with (25) and the traditional capital asset pricing model results as a special case.

The Esscher Principle

For $c=\infty$ the premium formula is

$$
\varepsilon\left(X, R^{M}\right)=\frac{E\left(X e^{-b R^{M}}\right)}{E\left(e^{-b R^{M}}\right)}, \quad b>0 .
$$

By assuming independence of the insurance risk $X$ and the non-insurance risk $K_{N} R^{N}$, one obtains in analogy with BÜHLMANN (1980) the Esscher principle:

$$
\varepsilon\left(X, R^{M}\right)=\frac{E\left(X e^{b^{\prime} X}\right)}{E\left(e^{b^{\prime} X}\right)} \quad \text { with } b^{\prime}=\frac{b}{K} .
$$

\section{CONCLUSIONS}

In this paper the connection between capital asset pricing and some results of risk theory was analysed. For all Neumann utilities belonging to the HARA-class, it 
was shown that the generalized capital asset pricing model may be interpreted as an extension of Bühlmann's economic premium principle to an economy with a non-insurance sector. In particular, it was possible to derive the variance and the Esscher principle from the CAPM-condition.

Finally, our analysis led to relationships between premiums for insurance and for non-insurance risks. These formulae could be considered as premium principles which are based on general capital market conditions.

\section{ACKNOWLEDGEMENTS}

I am indebted to H. Bühlmann, H. Garbers, P. Zweifel and two anonymous referees for very helpful suggestions.

\section{REFERENCES}

BORCH, K. (1986) Risk theory and serendipity. Insurance: Mathematics and Economics 5, 103-112. BüHLmann, H. (1980) An economic premium principle. ASTIN Bulletin 11, 52-60.

BühlmanN, H. (1984). The general economic premium principle. ASTIN Bulletin 14, 13-21.

Cass, D. and Stiglitz, J. E. (1970). The structure of investor preferences and asset returns, and separability in portfolio allocation: a contribution to the pure theory of mutual funds. Journal of Economic Theory 2, 122-160.

Goovaerts, M. J., de Vylder, F. and Haezendonck, J. (1984) Insurance premiums. NorthHolland, Amsterdam.

KAHANE, Y. (1979) The theory of insurance risk premiums - a re-examination in the light of recent developments in capital market theory. ASTIN Bulletin 10, 223-239.

LienhARD, M. (1986) Calculation of price equilibria for utility functions of the HARA class. ASTIN Bulletin 17 in press.

LiNTNER, J. (1965) The valuation of risk assets and the selection of risky investments in stock portfolios and capital budgets. Review of Economics and Statistics 47, 13-37.

Merton, R. C. (1982) On the microeconomic theory of investment under uncertainty. In Handboak of Mathematical Economics, Vol. II. North-Holland, Amsterdam.

SHARPE, W. F. (1964). Capital asset prices: a theory of market equilibrium under conditions of risk. Journal of Finance 19, 425-442.

HEINZ MÜLLER

Institut für Empirische Wirtschaftsforschung, Universität Zürich, Kleinstrasse 15, CH-8008 Zürich, Switzerland. 